\title{
Two-year prognostic value of mean platelet volume in patients with diabetes and stable coronary artery disease undergoing elective percutaneous coronary intervention
}

Ping Jiang, Ying Song, Jing-Jing Xu, Huan-Huan Wang, Lin Jiang, Wei Zhao, Xue-Yan Zhao, Jue Chen, Zhan Gao, Shu-Bin Qiao, Yue-Jin Yang, Run-Lin Gao, Bo Xu, Jin-Qing Yuan

State Key Laboratory of Cardiovascular Disease, National Center for Cardiovascular Diseases, Fuwai Hospital, Chinese Academy of Medical Sciences and Peking Union Medical College, Beijing, China

\begin{abstract}
Background: Mean platelet volume (MPV) is a marker of platelet size and activity, and is associated with a poor prognosis of cardiovascular disease. Studies have shown a relationship between diabetes mellitus (DM) and MPV. This study examined the relationship between admission MPV and 2-year cardiac mortality in patients with DM and stable coronary artery disease (SCAD) undergoing elective percutaneous coronary intervention (PCI).

Methods: A total of 1389 patients were enrolled and divided into two groups according to MPV as follows: lower $M P V(n=908, M P V \leq 10.9 \mathrm{fL})$ and higher $M P V(n=481, M P V>10.9 \mathrm{fL})$.

Results: Body mass index, platelet distribution width, MPV/platelet and glycated hemoglobin (HbA1c) levels were significantly higher in the higher MPV group compared with the lower MPV group (all $p<0.05)$. The platelet count was significantly lower in the higher MPV group compared with the lower MPV group $(p<0.05)$. MPV was positively associated with HbA1c and fasting plasma glucose levels ( $r=0.073$ and $0.061, p=0.007$ and 0.023 , respectively) in bivariate correlation analysis. The 2-year cardiac mortality rate was $0.7 \%$, and was significantly lower in the lower MPV group than in the higher $M P V$ group in Kaplan-Meier analysis $(p=0.019)$. Receiver operating characteristic analysis showed a good diagnostic value for MPV at predicting long-term cardiac mortality (area under the curve: 0.735 , 95\% confidence interval [CI]: 0.590-0.880, $p=0.01$ ). Elevated MPV was a significant risk factor for 2-year cardiac mortality (hazard ratio: 2.091, 95\% CI: 1.075-4.070, $p=0.030$ ) in multivariable Cox regression analysis.

Conclusions: Mean platelet volume is a strong, independent prognostic factor in PCI-treated patients with DM and SCAD. (Cardiol J 2019; 26, 2: 138-146)
\end{abstract}

Key words: diabetes mellitus, stable coronary artery disease, cardiac mortality, percutaneous coronary intervention

\section{Introduction}

Platelets play an important role in the onset of cardiovascular disease [1]. Platelet activation is as- sociated with death, myocardial infarction (MI), and other cardiovascular events [2,3]. Monitoring the function of platelets may help evaluate the severity of coronary artery disease (CAD) and prognosis.

Address for correspondence: Dr. Jin-Qing Yuan, Fuwai Hospital, National Center for Cardiovascular Diseases, Chinese Academy of Medical Sciences, A 167 Beilishi Road, Xicheng District, Beijing, 100037, China, tel: +86 13901064286, fax: 88322857, e-mail: dr_jinqingyuan@sina.com

Received: 25.02.2018

Accepted: 13.06.2018 
However, because testing platelet function is a time-consuming, costly, and technically challenging process, it is not widely used. Larger platelets contain more dense granules, express more adhesion receptors, and have higher thrombotic activity, which can reflect the degree of platelet activation $[4,5]$. Therefore, platelet volume has been proposed as an indicator of platelet reactivity. Mean platelet volume (MPV) is a precise measure of platelet size, and is reported during a complete blood count analysis. This index is cost-effective and accessible.

Previous studies have reported a relationship between MPV and diabetes mellitus (DM). Platelets of patients with DM are characterized by dysregulation of several signaling pathways, resulting in increased platelet reactivity [6]. Increased platelet size and activity may play a role in the observed higher risk for developing ST-segment elevation myocardial infarction (STEMI) and worse outcomes in patients with DM [7].

Previous studies have examined MPV in the development of CAD [3, 8-10]. MPV is an important factor for helping predict the prognosis of patients with $\mathrm{CAD}$ [6, 11-13]. Few studies have examined MPV in patients with stable CAD (SCAD) and DM. Additionally, the prognostic relevance of DM on clinical outcome is less apparent in Asian populations compared with Western populations $[14,15]$.

The current study aimed to examine the relationship between MPV at admission and clinical outcomes in patients with DM and SCAD undergoing elective percutaneous coronary intervention (PCI). This study also aimed to evaluate whether this index can be used as a marker of long-term prognosis.

\section{Methods}

\section{Study population}

Patients enrolled were admitted to Fuwai Hospital were diagnosed with SCAD, and underwent elective PCI between January 2013 and December 2013. The study was conducted in accordance with the principles contained within the Declaration of Helsinki, and the Institutional Review Board of Fuwai Hospital approved the study protocol. All participants provided written informed consent before the intervention.

\section{Laboratory examination and procedural details}

Venous blood samples were collected at admission in standardized dipotassium EDTA tubes. Samples were tested within $2 \mathrm{~h}$ of collection to minimize variations due to sample aging. MPV and platelets were measured using an automated blood counter (Sysmex XN-2000 Hematology System; Sysmex Corp., Kobe, Japan). Before the procedure, if patients with elective PCI were not taking long-term acetylsalicylic acid and clopidogrel, they received a loading dose of clopidogrel $(300 \mathrm{mg}$ ). Coronary angiography and PCI were performed using standard protocols and guidelines.

\section{Definitions and endpoints}

Patients were divided into three groups according to the MPV value ( $\leq 10.1 \mathrm{fL}$, group 1 ; 10.1-10.9 fL, group 2; > $10.9 \mathrm{fL}$, group 3). Groups 1 and 2 were combined and defined as the lower MPV group ( $\leq 10.9 \mathrm{fL}$ ) and group 3 was defined as the higher MPV group ( $>10.9 \mathrm{fL}$ ). DM was defined as follows: (a) Pre-existing condition diagnosed before admission (patients on insulin, oral glucose-lowering drugs, or therapeutic diet); and (b) Newly diagnosed DM based on fasting plasma glucose (FPG) levels $\geq 7.0 \mathrm{mmol} / \mathrm{L}$ or 2 - $\mathrm{h}$ plasma glucose levels $\geq 11.1 \mathrm{mmol} / \mathrm{L}$ during an oral glucose tolerance test [16]. SCAD was generally characterized by episodes of reversible myocardial demand/supply mismatch related to ischemia or hypoxia usually induced by exercise, emotion, or other stresses, but it may have also spontaneously occurred. Such episodes of ischemia/hypoxia were commonly associated with transient chest discomfort (angina pectoris). SCAD also included stabilized, often asymptomatic, phases that follow acute coronary syndrome (ACS) [17]. Death that could not be attributed to a noncardiac etiology was considered as cardiac mortality, such as intra-stent thrombosis, MI, and sudden death in this cohort.

\section{Follow-up of patients}

All patients were scheduled for a 2 -year clinical follow-up. Patients were clinically monitored for major cardiovascular events. The primary endpoint was cardiac mortality. Follow-up data were obtained at 30 days, 6 months, 1 year, and 2 years by telephone calls, out-patient follow-ups, or letters. Patients were advised to return for coronary angiography if clinically indicated by symptoms or documentation of myocardial ischemia.

\section{Statistical analysis}

Continuous variables are presented as mean \pm standard deviation (SD) or median (interquartile range) and were compared using the Student t-test or Mann-Whitney U test, as appropriate. The Shapiro-Wilk test was used to determine whether ran- 
dom samples had a normal distribution. Categorical variables are presented as numbers and percentages, and were compared using the $\chi^{2}$ test or the Fisher exact test. In-hospital and 2-year survival was evaluated using the Kaplan-Meier method and compared using the log-rank test. Relationships between MPV and variables were estimated using the Spearman rank correlation coefficient. Receiver operating characteristic (ROC) curves were estimated for MPV. ROC analysis was used to identify possible cut-offs for predicting 2-year cardiac mortality. Clinically important variables (age, sex, body mass index, hypertension, hyperlipidemia, ejection fraction, estimated glomerular filtration rate, high-sensitivity C-reactive protein) were entered into multivariate Cox analysis. Multivariate analysis was performed to estimate hazard ratios (HRs) and 95\% confidence intervals (95\% CIs) for identifying independent predictors of 2-year cardiac mortality, while adjusting for potential confounders. A two-tailed $\mathrm{p}$ value $<0.05$ was considered statistically significant. Statistical analyses were performed using SPSS 23.0 (SPSS Inc., College Station, TX).

\section{Results}

A total of 1389 consecutive patients were enrolled. Follow-up at 2 years was completed for $1380(99.4 \%)$ patients.

\section{Patient characteristics and outcomes according to MPV level and DM}

Baseline characteristics according to MPV and DM are shown in Table 1. The higher MPV group had a higher body mass index $(\mathrm{p}=0.003)$, platelet distribution width $(\mathrm{p}<0.001)$, MPV/PLT $(\mathrm{p}<0.001)$, and glycated hemoglobin $(\mathrm{HbA1c})$ levels $(p=0.023)$, but a lower platelet count $(\mathrm{p}<0.001)$, compared with the lower MPV group. Angiographic characteristics according to MPV are shown in Table 2. The higher MPV group had a higher SYNTAX score and more often had severe CAD (left main stenosis and/or 3-vessel disease) compared with the lower MPV group, but these differences were not significant. There were no significant differences in lesions of the left anterior descending, left circumflex coronary, and right coronary arteries between the groups.

\section{Effect of high MPV on cardiac mortality of patients with DM}

Over the 2-year follow-up, 3 of 908 patients died in the lower MPV group and 7 of 481 patients died in the higher MPV group for cardiac reasons $(\mathrm{p}=0.038)$ (Table 3). Among all patients, 7 died of stent thrombosis, 1 died of MI, and 2 died of sudden cardiac death. The cardiac mortality rate was $0.7 \%$. Kaplan-Meier survival analysis showed a higher 2-year cardiac mortality rate in the higher MPV group than in the lower MPV group $(\mathrm{p}=0.019)$ (Fig. 1). Cox regression showed that MPV was significantly associated with 2 -year cardiac mortality when analyzed as a continuous variable in the univariate model $(\mathrm{HR}=2.090,95 \% \mathrm{CI}: 1.217-3.589$, $\mathrm{p}=0.008$ ) and multivariate models. Similar findings were observed when MPV was analyzed as a binary variable (Table 4 ).

\section{Patients with DM with or without requirement for insulin}

Mean platelet volume was similar in patients with $\mathrm{DM}$ who required insulin and those who did not require insulin $(\mathrm{p}=0.853)$. No significant difference in cardiac mortality was observed between patients with or without insulin $(\mathrm{p}=0.986)$. Cox regression analysis showed no significant difference between patients with or without insulin $(\mathrm{HR}=0.892,95 \%$ CI: $0.230-3.463, \mathrm{p}=0.869)$.

\section{ROC analysis}

In patients with DM, ROC analysis showed good diagnostic value for MPV at predicting 2-year cardiac mortality (area under the curve $=0.735$, 95\% CI: $0.590-0.880, \mathrm{p}=0.01$ ) (Fig. 2). The cut-off value was $10.65 \mathrm{fL}$.

Bivariate analysis of MPV, HbA1c, and FPG

Mean platelet volume was significantly positively correlated with $\mathrm{HbA1c}(\mathrm{r}=0.073, \mathrm{p}=0.007)$ and FPG levels $(r=0.061, p=0.023)$ in bivariate analysis (Fig. 3).

\section{Discussion}

In this study, the relationship between MPV at admission and 2-year cardiac mortality in patients with DM and SCAD who underwent elective PCI was examined. The present study found that: 1) The cardiac mortality rate was significantly higher in the higher MPV group compared with the lower MPV group, 2) MPV was positively correlated with HbA1c and FPG levels, although the association was weak, and 3) MPV was not associated with the extent of CAD.

Mean platelet volume is influenced by multiple risk factors for $\mathrm{CAD}$, including $\mathrm{DM}$, impaired fasting glucose, hyperlipidemia, and metabolic 
Table 1. Basic characteristics of the study population.

\begin{tabular}{|c|c|c|c|}
\hline & $M P V \leq 10.9(n=908)$ & MPV $>10.9(n=481)$ & $\mathbf{P}$ \\
\hline Age [years] & $59.2 \pm 9.5$ & $58.7 \pm 9.4$ & 0.409 \\
\hline Sex (male) & $691(76.1 \%)$ & $367(76.3 \%)$ & 0.934 \\
\hline Weight $[\mathrm{kg}]$ & $74.2 \pm 11.3$ & $76.2 \pm 11.6$ & 0.002 \\
\hline $\mathrm{BMI}\left[\mathrm{kg} / \mathrm{m}^{2}\right]$ & $26.1 \pm 3.1$ & $26.7 \pm 3.3$ & 0.003 \\
\hline Systolic BP [mmHg] & $129.2 \pm 16.6$ & $129.9 \pm 17.2$ & 0.475 \\
\hline LVEF [\%] & $63.4 \pm 7.5$ & $63.0 \pm 6.9$ & 0.329 \\
\hline \multicolumn{4}{|l|}{ Past medical history: } \\
\hline Dyslipidemia & $698(76.9 \%)$ & $340(70.7 \%)$ & 0.012 \\
\hline Smoker: & & & 0.615 \\
\hline Active smoker & $482(53.1 \%)$ & $267(55.5 \%)$ & \\
\hline Previous smoker & $15(1.7 \%)$ & $6(1.2 \%)$ & \\
\hline Hypertension & $621(68.4 \%)$ & $337(70.1 \%)$ & 0.522 \\
\hline Previous MI & $227(25.0 \%)$ & $141(29.3 \%)$ & 0.083 \\
\hline Previous $\mathrm{PCl}$ & $290(31.9 \%)$ & $135(28.1 \%)$ & 0.136 \\
\hline Previous CABG & $40(4.4 \%)$ & $32(6.7 \%)$ & 0.072 \\
\hline Previous CVD & $114(12.6 \%)$ & $59(12.3 \%)$ & 0.877 \\
\hline \multicolumn{4}{|l|}{ Laboratory finding: } \\
\hline Platelet count $\left[\times 10^{9} / \mathrm{L}\right]$ & $206.7 \pm 50.6$ & $173.5 \pm 45.4$ & $<0.001$ \\
\hline MPV/PLT & $0.05 \pm 0.01$ & $0.07 \pm 0.02$ & $<0.001$ \\
\hline Hemoglobin [g/L] & $142.1 \pm 16.1$ & $143.8 \pm 14.5$ & 0.049 \\
\hline Hematocrit [\%] & $41.4 \pm 4.2$ & $42.1 \pm 3.9$ & 0.004 \\
\hline WBC $\left[\times 10^{9} / L\right]$ & $6.72 \pm 1.71$ & $6.72 \pm 1.77$ & 0.949 \\
\hline $\mathrm{RBC}\left[\times 10^{12} / \mathrm{L}\right]$ & $4.64 \pm 0.52$ & $4.69 \pm 0.50$ & 0.059 \\
\hline RDW [\%] & $12.8 \pm 0.6$ & $12.8 \pm 0.7$ & 0.177 \\
\hline PDW [\%] & $11.5 \pm 1.0$ & $14.8 \pm 1.6$ & $<0.001$ \\
\hline $\mathrm{FPG}[\mathrm{mmol} / \mathrm{L}]$ & $7.4 \pm 2.3$ & $7.6 \pm 2.5$ & 0.061 \\
\hline eGFR $\left[\mathrm{mL} / \mathrm{min} / 1.73 \mathrm{~m}^{2}\right]$ & $91.9 \pm 14.5$ & $91.2 \pm 15.8$ & 0.379 \\
\hline $\mathrm{HbA} 1 \mathrm{c}[\%]$ & $7.7 \pm 1.3$ & $7.8 \pm 1.4$ & 0.023 \\
\hline $\mathrm{hsCRP}[\mathrm{mg} / \mathrm{L}]$ & $1.47(0.77,3.07)$ & $1.44(0.73,3.17)$ & 0.539 \\
\hline BNP [pmol/L] & $444(568,748)$ & $591(447,791)$ & 0.262 \\
\hline ET-1 [pmol/L] & $0.29 \pm 0.17$ & $0.30 \pm 0.15$ & 0.396 \\
\hline Uric acid [mg/dL] & $5.52 \pm 1.34$ & $5.64 \pm 1.45$ & 0.128 \\
\hline $\mathrm{TG}[\mathrm{mmol} / \mathrm{L}]$ & $1.47(1.12,2.05)$ & $1.56(1.12,2.23)$ & 0.076 \\
\hline $\mathrm{TC}[\mathrm{mmol} / \mathrm{L}]$ & $3.86(3.30,4.64)$ & $3.90(3.35,4.72)$ & 0.556 \\
\hline $\mathrm{HDL}-\mathrm{C}[\mathrm{mmol} / \mathrm{L}]$ & $0.99(0.84,1.14)$ & $0.97(0.81,1.14)$ & 0.120 \\
\hline LDL-C [mmol/L] & $2.20(1.77,2.83)$ & $2.24(1.78,2.81)$ & 0.876 \\
\hline \multicolumn{4}{|c|}{ Concomitant medication in hospital: } \\
\hline Acetylsalicylic acid & $901(99.2 \%)$ & $475(98.8 \%)$ & 0.380 \\
\hline Clopidogrel & $896(98.7 \%)$ & $476(99.0 \%)$ & 0.649 \\
\hline Beta-blocker & $849(93.5 \%)$ & $439(91.3 \%)$ & 0.127 \\
\hline Statins & $860(94.7 \%)$ & $459(95.4 \%)$ & 0.564 \\
\hline
\end{tabular}

Data are presented as number (percentage) for categorical data and mean \pm standard deviation) or median (interquartile range) for continuous data, depending on distribution of the data. Hypertension was defined as systolic blood pressure $\geq 140 \mathrm{mmHg}$, diastolic blood pressure $\geq 90 \mathrm{mmHg}$, or use of antihypertensive medication. Dyslipidemia was defined as total cholesterol levels $>5.98 \mathrm{mmol} / \mathrm{L}$, low-density lipoprotein levels $\geq 2.59 \mathrm{mmol} / \mathrm{L}$, or high-density lipoprotein levels $\leq 1.59 \mathrm{mmol} / \mathrm{L}$. The estimated glomerular filtration rate was calculated using the Chronic Kidney Disease Epidemiology Collaboration Study equation.

$\mathrm{BMI}$ - body mass index; BNP - B-type natriuretic peptide; BP — blood pressure; CABG — coronary artery bypass grafting; CVD - cardiovascular disease; eGFR - estimated glomerular filtration rate; ET-1 — endothelin-1; FPG — fasting plasma glucose; HbAlc - glycated hemoglobin; HDL-C — high-density lipoprotein cholesterol; hs-CRP — high-sensitivity C-reactive protein; LDL-C - low-density lipoprotein cholesterol; LVEF - left ventricular ejection fraction; $\mathrm{MI}$ - myocardial infarction; MPV - mean platelet volume; PCI - percutaneous coronary intervention; PDW — platelet distribution width; RBC — red blood cells; RDW — red cell distribution width; TC - totalcholesterol; TG - triglycerides; WBC - white blood cells 
Table 2. Angiographic and procedural characteristics.

\begin{tabular}{|c|c|c|c|}
\hline & $\begin{array}{c}M P V \leq 10.9 \\
(n=908)\end{array}$ & $\begin{array}{c}M P V>10.9 \\
(n=481)\end{array}$ & $\mathbf{P}$ \\
\hline \multicolumn{4}{|l|}{ Angiographic features: } \\
\hline Multivessel disease & $743(71.8 \%)$ & $410(85.2 \%)$ & 0.266 \\
\hline LM/trivessel disease & $483(53.2 \%)$ & $272(56.5 \%)$ & 0.232 \\
\hline \multicolumn{4}{|l|}{ Artery treated: } \\
\hline LM & $21(2.3 \%)$ & $16(3.3 \%)$ & 0.264 \\
\hline LAD & $811(89.3 \%)$ & $420(87.3 \%)$ & 0.264 \\
\hline LCX & $171(18.8 \%)$ & $86(17.9 \%)$ & 0.663 \\
\hline RCA & $168(18.5 \%)$ & $117(24.3 \%)$ & 0.011 \\
\hline Complex type C lesions & $528(58.1 \%)$ & $284(59.0 \%)$ & 0.865 \\
\hline Lesion length [mm] & $32.4 \pm 18.6$ & $33.2 \pm 17.0$ & 0.445 \\
\hline Vessel diameter [mm] & $3.10 \pm 0.51$ & $3.11 \pm 0.52$ & 0.564 \\
\hline Calcified lesions & $540(59.5 \%)$ & $269(55.9 \%)$ & 0.161 \\
\hline Bifurcation & $132(14.5 \%)$ & $85(17.7 \%)$ & 0.126 \\
\hline Intracoronary thrombus & $40(4.5 \%)$ & $16(3.4 \%)$ & 0.242 \\
\hline Chronic occlusion & $179(19.7 \%)$ & $92(19.1 \%)$ & 0.793 \\
\hline In-stent restenosis & $42(4.6 \%)$ & $24(5.0 \%)$ & 0.525 \\
\hline PMI & $12(1.3 \%)$ & $3(0.6 \%)$ & 0.231 \\
\hline SYNTAX score & $13.0 \pm 8.3$ & $13.2 \pm 7.7$ & 0.541 \\
\hline TIMI flow: & & & 0.807 \\
\hline 3 & $872(96.0 \%)$ & $462(96.0 \%)$ & \\
\hline 2 & $11(1.2 \%)$ & $6(1.2 \%)$ & \\
\hline 1 & $5(0.6 \%)$ & $1(0.2 \%)$ & \\
\hline 0 & $20(2.2 \%)$ & $12(2.5 \%)$ & \\
\hline Successful PCI & $856(94.3 \%)$ & $464(96.5 \%)$ & 0.181 \\
\hline Stent implantation & $844(93.0 \%)$ & $457(95.0 \%)$ & 0.134 \\
\hline
\end{tabular}

Data are presented as number (percentage) for categorical data and mean \pm standard deviation for continuous data. LAD - left anterior descending artery; LCX — left circumflex coronary artery; LM — left main; MPV — mean platelet volume; RCA — right coronary artery; $\mathrm{PMI}$ - periprocedural myocardial infarction; TIMI - Thrombolysis in Myocardial Infarction

Table 3. Two-year follow-up clinical outcomes.

\begin{tabular}{lccc}
\hline & $\begin{array}{c}\text { MPV } \leq \mathbf{1 0 . 9} \\
\text { (n = 908) }\end{array}$ & $\begin{array}{c}\text { MPV > 10.9 } \\
\text { (n = 481) }\end{array}$ & P \\
\hline All-cause death & $10(1.1 \%)$ & $9(1.9 \%)$ & 0.237 \\
Cardiac mortality & $3(0.3 \%)$ & $7(1.5 \%)$ & 0.038 \\
Myocardial infarction & $21(2.3 \%)$ & $5(1.0 \%)$ & 0.143 \\
Revascularization & $82(9.0 \%)$ & $47(9.8 \%)$ & 0.651 \\
TVR & $55(6.1 \%)$ & $30(6.2 \%)$ & 0.894 \\
TLR & $46(5.1 \%)$ & $22(4.6 \%)$ & 0.686 \\
Stent thrombosis & $10(1.1 \%)$ & $4(0.8 \%)$ & 0.782 \\
Stroke & $15(1.7 \%)$ & $7(1.5 \%)$ & 0.780 \\
Bleeding & $59(6.5 \%)$ & $32(6.7 \%)$ & 0.912 \\
Severe bleeding & $4(0.4 \%)$ & $0(0.0 \%)$ & 0.305 \\
MACE & $116(12.8 \%)$ & $65(13.5 \%)$ & 0.697 \\
\hline
\end{tabular}

Data are presented as number (percentage). MACE - major adverse cardiovascular events; MPV — mean platelet volume; TLR - target lesion revascularization; TVR - target vessel revascularization 


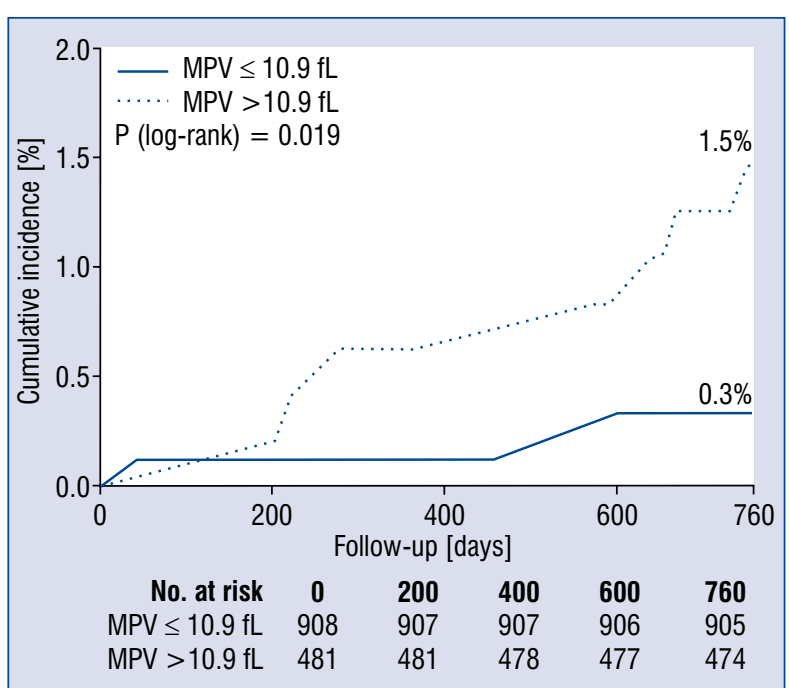

Figure 1. Kaplan-Meier curves for cardiac mortality. Cumulative Kaplan-Meier event curves for 2-year cardiac mortality were significantly higher in the higher mean platelet volume (MPV) group than in the lower MPV group.

syndrome [18-20]. In a study of 1411 patients [10], MPV was found to correlate with the frequency of DM and baseline glycemia. Shimodaira et al. [21] found that in prediabetic and normoglycemic patients, MPV was positively correlated with FPG levels. Verdoia et al. [22] also observed a similar phenomenon in their study of 3414 patients who underwent coronary angiography. In this study, it was found that MPV was positively correlated with HbA1c and FPG levels, but this association was weak. A possible reason for this finding may be that some other features, such as hypertension and other metabolic disorders, in addition to diabetes, affected platelet size.

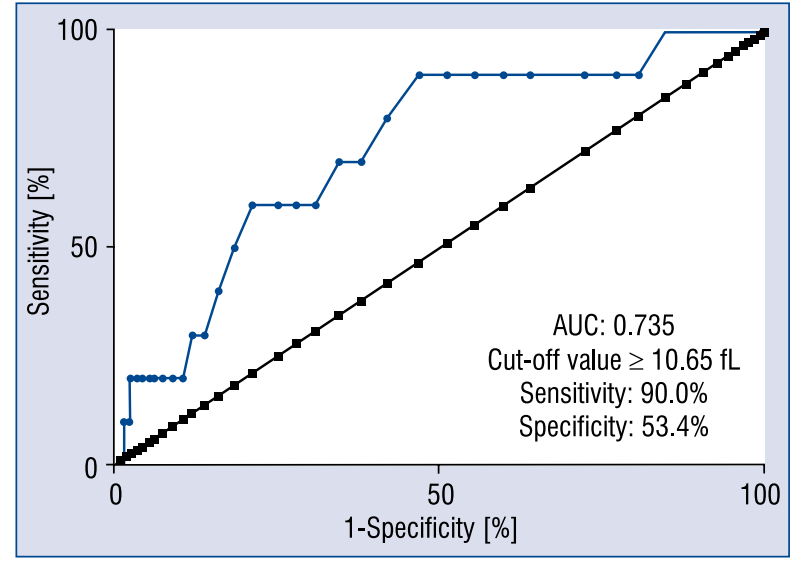

Figure 2. Receiver operating characteristic curve of mean platelet volume for predicting 2-year cardiac mortality; AUC - area under the curve.

Previous studies on the relationship between MPV and the severity of CAD in patients with DM are inconsistent. Sahin et al. [23] found that increased MPV was positively associated with the severity of CAD in patients with STEMI and DM. Abali et al. [24] reported that a high MPV may be an effective marker in determining the severity of CAD in patients with DM, and that a high MPV level may be associated with CAD pathophysiology in patients with DM. However, Lekston et al. [6] did not find a relationship between MPV and the number of diseased coronary arteries in patients with STEMI and DM who received primary PCI. In the current study, MPV in patients with DM who received elective PCI was examined. It was found that the incidence rate of left main and/or 3-vessel disease and SYNTAX score appeared to be higher in the

Table 4. Association between mean platelet volume and cardiac mortality.

\begin{tabular}{lccc}
\hline & HR & $95 \% \mathrm{Cl}$ & P \\
\hline MPV (per 1 fL increment) & 2.090 & $1.217-3.589$ & 0.008 \\
Model 1 & 2.063 & $1.218-3.494$ & 0.007 \\
Model 2 & 2.016 & $1.051-3.870$ & 0.035 \\
Model 3 & 2.091 & $1.075-4.070$ & 0.030 \\
MPV (2 groups) & 4.401 & $1.138-17.017$ & 0.032 \\
Model 1 & 4.577 & $1.181-17.737$ & 0.028 \\
Model 2 & 5.652 & $1.270-25.146$ & 0.023 \\
Model 3 & 5.773 & $1.283-25.981$ & 0.022 \\
\hline
\end{tabular}

Model 1: Adjusted for age, sex, and body mass index.

Model 2: Model $1+$ hypertension, hyperlipidemia, and left ventricular ejection fraction.

Model 3: Model 2 + estimated glomerular filtration rate and high-sensitivity C-reactive protein.

$\mathrm{Cl}$ - confidence interval; $\mathrm{HR}$ - hazard ratio 


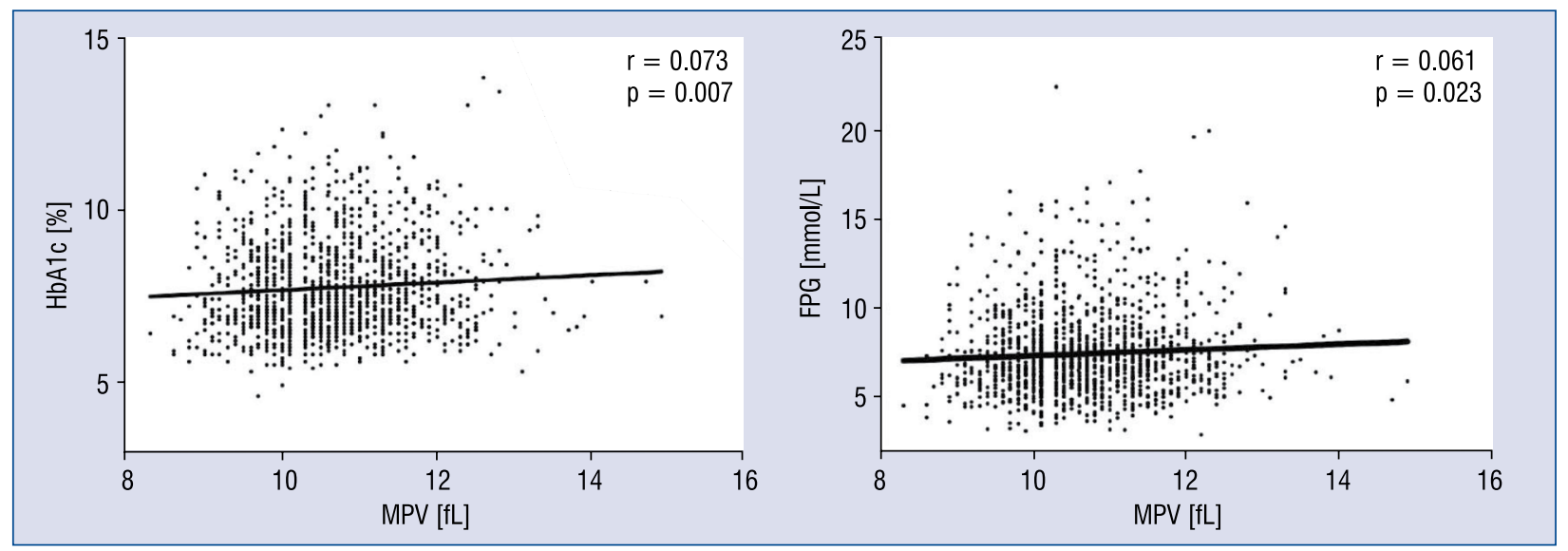

Figure 3. Correlation analysis. Mean platelet volume (MPV) was positively correlated with glycated hemoglobin (HbA1c) levels (A) and MPV was positively correlated with fasting plasma glucose (FPG) levels (B).

higher MPV group, but this was not significant. Further studies are required to determine the relationship between MPV and the severity of CAD in patients with DM.

Previous studies have reported that preprocedural elevated MPV is associated with the incidence of major adverse cardiac events following PCI [25]. Most of these studies were conducted in patients with ACS. A meta-analysis [26] reported that MPV was higher in patients who developed cardiovascular events than in non-cardiovascular event patients, particularly those with MI and death. MPV may be a predictive factor of future MI or death in patients with ACS. Lekston et al. [6] studied the association between MPV at admission and clinical outcomes in patients with DM and STEMI. They found that MPV had good prognostic value for in-hospital and late mortality. In the current study, it was found that MPV had good prognostic value for 2-year cardiac mortality in patients with DM and SCAD, which is consistent with previous studies. However, Shah et al. [27] analyzed MPV in 1512 patients who received PCI and did not find any correlation between MPV and long-term mortality. A possible reason for this lack of findings is that they enrolled diabetic and non-diabetic patients.

The possible mechanisms behind increased major cardiovascular events in patients with high MPV may be an increase in platelet activity and aggregation. Platelet turnover also increases in these patients. There is an increased release of young, large, and reactive platelets from megakaryocytes in bone marrow, which results in an increased measurement of MPV. High platelet turnover has been reported to be associated with soluble P-selectin (a platelet activation marker), platelet aggregation [28], and inadequate responses to antiplatelet drugs [29, 30]. Platelets in people with type $2 \mathrm{DM}$ adhere to the vascular endothelium and aggregate more readily than those in healthy people. Loss of sensitivity to the normal restraints exercised by prostacyclin and nitric oxide generated by the vascular endothelium is a major defect in platelet function. Insulin is a natural antagonist of platelet hyperactivity. Insulin sensitizes platelets to PGI2 and enhances endothelial generation of PGI2 and nitric oxide. Defects in the action of insulin in DM create a condition of disordered platelet activity, which is conducive to macrovascular and microvascular events [31].

\section{Limitations of the study}

This study has some limitations. First, this was an observational, single-center study and was thus prone to bias and unintentional confounding. Second, we did not assess platelet function at the same time. Finally, the cohort only included those who underwent elective PCI rather than PCI following ACS. Therefore, the rate of major cardiovascular events was lower compared with similar previous studies.

\section{Conclusions}

Mean platelet volume is a strong, independent prognostic factor in PCI-treated patients with DM and SCAD. 


\section{Acknowledgements}

This study was supported by the National Key Technology R\&D Program in the $13^{\text {th }}$ Five-Year Plan of China (No. 2016YFC1301301); and the National Natural Science Foundation of China (81770365). We thank Alexander Pishief, LLB, BBmedSc, from Liwen Bianji, Edanz Group China (www.liwenbianji.cn/ac), for editing the English text of a draft of this manuscript.

\section{Conflict of interest: None declared}

\section{References}

1. Falk E. Pathogenesis of atherosclerosis. J Am Coll Cardiol. 2006; 47(8 Suppl): C7-12.

2. Martin JF, Bath PM, Burr ML. Influence of platelet size on outcome after myocardial infarction. Lancet. 1991; 338(8780): 1409-1411, indexed in Pubmed: 1683417.

3. Chu SG, Becker RC, Berger PB, et al. Mean platelet volume as a predictor of cardiovascular risk: a systematic review and meta-analysis. J Thromb Haemost. 2010; 8(1): 148-156, doi: $10.1111 / \mathrm{j} .1538-7836.2009 .03584 . x$, indexed in Pubmed: 19691485 .

4. Jakubowski JA, Adler B, Thompson CB, et al. Influence of platelet volume on the ability of prostacyclin to inhibit platelet aggregation and the release reaction. J Lab Clin Med. 1985; 105(2): 271-276, indexed in Pubmed: 3882862.

5. Bath PM, Butterworth RJ. Platelet size: measurement, physiology and vascular disease. Blood Coagul Fibrinolysis. 1996; 7(2): 157-161, indexed in Pubmed: 8735807.

6. Lekston A, Hudzik B, Hawranek M, et al. Prognostic significance of mean platelet volume in diabetic patients with ST-elevation myocardial infarction. J Diabetes Complications. 2014; 28(5): 652-657, doi: 10.1016/j.jdiacomp.2014.05.002, indexed in Pubmed: 24942286 .

7. Ferreiro JL, Angiolillo DJ. Diabetes and Antiplatelet Therapy in Acute Coronary Syndrome. Circulation. 2011; 123(7): 798-813, doi: 10.1161/circulationaha.109.913376.

8. Yüksel Kalkan G, Gür M, Baykan AO, et al. Mean platelet volume is associated with aortic intima-media thickness in patients without clinical manifestation of atherosclerotic cardiovascular disease. Anatol J Cardiol. 2015; 15(9): 753-758, doi: 10.5152/ akd.2014.5576, indexed in Pubmed: 25592097.

9. Endler G, Klimesch A, Sunder-Plassmann H, et al. Mean platelet volume is an independent risk factor for myocardial infarction but not for coronary artery disease. Br J Haematol. 2002; 117(2): 399-404, indexed in Pubmed: 11972524.

10. De Luca G, Santagostino M, Secco GG, et al. Mean platelet volume and the extent of coronary artery disease: results from a large prospective study. Atherosclerosis. 2009; 206(1): 292-297, doi: 10.1016/j.atherosclerosis.2009.02.008, indexed in Pubmed: 19426979.

11. Ndrepepa G, Tiroch K, Fusaro M, et al. 5-year prognostic value of no-reflow phenomenon after percutaneous coronary intervention in patients with acute myocardial infarction. J Am Coll Cardiol. 2010; 55(21): 2383-2389, doi: 10.1016/j.jacc.2009.12.054, indexed in Pubmed: 20488311.
12. Eisen A, Bental T, Assali A, et al. Mean platelet volume as a predictor for long-term outcome after percutaneous coronary intervention. J Thromb Thrombolysis. 2013; 36(4): 469-474, doi: 10.1007/s11239-013-0876-1, indexed in Pubmed: 23345043.

13. Rechciński T, Jasińska A, Foryś J, et al. Prognostic value of platelet indices after acute myocardial infarction treated with primary percutaneous coronary intervention. Cardiol J. 2013; 20(5): 491-498, doi: 10.5603/CJ.2013.0134, indexed in Pubmed: 24469872.

14. Park DW, Park SW, Park KH, et al. Frequency of and risk factors for stent thrombosis after drug-eluting stent implantation during long-term follow-up. Am J Cardiol. 2006; 98(3): 352-356, doi: 10.1016/j.amjcard.2006.02.039, indexed in Pubmed: 16860022.

15. Park DW, Flaherty JD, Davidson CJ, et al. Prognostic influence of diabetes mellitus on long-term clinical outcomes and stent thrombosis after drug-eluting stent implantation in asian patients. Am J Cardiol. 2009; 103(5): 646-652, doi: 10.1016/j.amjcard.2008.11.012, indexed in Pubmed: 19231327.

16. Rydén L, Standl E, Bartnik M, et al. Task Force on Diabetes and Cardiovascular Diseases of the European Society of Cardiology (ESC), European Association for the Study of Diabetes (EASD). Guidelines on diabetes, pre-diabetes, and cardiovascular diseases: executive summary. The Task Force on Diabetes and Cardiovascular Diseases of the European Society of Cardiology (ESC) and of the European Association for the Study of Diabetes (EASD). Eur Heart J. 2007; 28(1): 88-136, doi: 10.1093/eurheartj/ehl260, indexed in Pubmed: 17220161.

17. Montalescot G, Sechtem U, Achenbach S, et al. Task Force Members, ESC Committee for Practice Guidelines, Document Reviewers. 2013 ESC guidelines on the management of stable coronary artery disease: the Task Force on the management of stable coronary artery disease of the European Society of Cardiology. Eur Heart J. 2013; 34(38): 2949-3003, doi: 10.1093/ eurheartj/eht296, indexed in Pubmed: 23996286.

18. Coban E, Bostan F, Ozdogan M. The mean platelet volume in subjects with impaired fasting glucose. Platelets. 2009; 17(1): 67-69, doi: 10.1080/09537100500220729.

19. Coban E, Ozdogan M, Yazicioglu G, et al. The mean platelet volume in patients with obesity. Int J Clin Pract. 2005; 59(8): 981-982, doi: 10.1111/j.1742-1241.2005.00500.x, indexed in Pubmed: 16033624 .

20. Nadar SK, Blann AD, Kamath S, et al. Platelet indexes in relation to target organ damage in high-risk hypertensive patients: a substudy of the Anglo-Scandinavian Cardiac Outcomes Trial (ASCOT). J Am Coll Cardiol. 2004; 44(2): 415-422, doi: 10.1016/j. jacc.2004.03.067, indexed in Pubmed: 15261941.

21. Shimodaira M, Niwa T, Nakajima K, et al. Correlation between mean platelet volume and fasting plasma glucose levels in prediabetic and normoglycemic individuals. Cardiovasc Diabetol. 2013; 12: 14, doi: 10.1186/1475-2840-12-14, indexed in Pubmed: 23311535.

22. Verdoia M, Schaffer A, Barbieri L, et al. Novara Atherosclerosis Study (NAS) group. Diabetes, glucose control and mean platelet volume: a single-centre cohort study. Diabetes Res Clin Pract. 2014; 104(2): 288-294, doi: 10.1016/j.diabres.2013.12.020, indexed in Pubmed: 24530116.

23. Sahin DY, Gür M, Elbasan Z, et al. Mean platelet volume and extent and complexity of coronary artery disease in diabetic and nondiabetic patients with ST elevation myocardial infarction. Angiology. 2013; 64(7): 505-511, doi: 10.1177/0003319712460423, indexed in Pubmed: 23028178. 
24. Abalı G, Akpınar O, Söylemez N. Correlation of the coronary severity scores and mean platelet volume in diabetes mellitus. Adv Ther. 2014; 31(1): 140-148, doi: 10.1007/s12325-013-0081-9, indexed in Pubmed: 24318519.

25. Ki YJ, Park S, Ha SI, et al. Usefulness of mean platelet volume as a biomarker for long-term clinical outcomes after percutaneous coronary intervention in Korean cohort: a comparable and additive predictive value to high-sensitivity cardiac troponin $\mathrm{T}$ and $\mathrm{N}$-terminal pro-B type natriuretic peptide. Platelets. 2014; 25(6): 427-432, doi: 10.3109/09537104.2013.835393, indexed in Pubmed: 24102424.

26. Sansanayudh N, Numthavaj P, Muntham D, et al. Prognostic effect of mean platelet volume in patients with coronary artery disease. A systematic review and meta-analysis. Thromb Haemost. 2015; 114(6): 1299-1309, doi: 10.1160/TH15-04-0280, indexed in Pubmed: 26245769.

27. Shah B, Oberweis B, Tummala L, et al. Mean platelet volume and long-term mortality in patients undergoing percutaneous coronary intervention. Am J Cardiol. 2013; 111(2): 185-189, doi: 10.1016/j. amjcard.2012.09.014, indexed in Pubmed: 23102880.
28. Grove EL, Hvas AM, Mortensen SB, et al. Effect of platelet turnover on whole blood platelet aggregation in patients with coronary artery disease. J Thromb Haemost. 2011; 9(1): 185-191, doi: 10.1111/j.1538-7836.2010.04115.x.

29. Guthikonda S, Lev EI, Patel R, et al. Reticulated platelets and uninhibited COX-1 and COX-2 decrease the antiplatelet effects of aspirin. J Thromb Haemost. 2007; 5(3): 490-496, doi: 10.1111/j.1538-7836.2007.02387.x, indexed in Pubmed: 17319904.

30. Guthikonda S, Alviar CL, Vaduganathan M, et al. Role of reticulated platelets and platelet size heterogeneity on platelet activity after dual antiplatelet therapy with aspirin and clopidogrel in patients with stable coronary artery disease. J Am Coll Cardiol. 2008; 52(9): 743-749, doi: 10.1016/j.jacc.2008.05.031, indexed in Pubmed: 18718422.

31. Vinik AI, Erbas T, Park TS, et al. Platelet dysfunction in type 2 diabetes. Diabetes Care. 2001; 24(8): 1476-1485, indexed in Pubmed: 11473089. 